\title{
Barriers to Including Indigenous Content in Canadian Health Professions Curricula
}

Nicole Doria

Dalhousie University

Maya Biderman

Dalhousie University

Jad Sinno

Dalhousie University

Jordan Boudreau

Dalhousie University

Michael P. Mackley

Dalhousie University

Amy Bombay

Dalhousie University

Canadian Journal of Education / Revue canadienne de l'éducation 44:3 (2021)

(c)2021 Canadian Society for the Study of Education/ Société canadienne pour l'étude de l'éducation 


\begin{abstract}
Indigenous peoples in Canada continue to face health care inequities despite their increased risk for various negative health outcomes. Evidence suggests that health professions students and faculty do not feel their curriculum adequately prepares learners to address these inequities. The aim of this study was to identify barriers that hinder the inclusion of adequate Indigenous content in curricula across health professions programs. Semi-structured interviews were conducted with 33 faculty members at a university in Canada from various health disciplines. Employing thematic analysis, four principal barriers were identified: (1) the limited number and overburdening of Indigenous faculty, (2) the need for non-Indigenous faculty training and capacity, (3) the lack of oversight and direction regarding curricular content and training approaches, and (4) the limited amount of time in curriculum and competing priorities. Addressing these barriers is necessary to prepare learners to provide equitable health care for Indigenous peoples.

Keywords: Indigenous health, health professions, curricula, faculty perspectives, barriers, Canada
\end{abstract}

\title{
Résumé
}

Malgré leur risque accru de développer des ennuis de santé, les Autochtones du Canada continuent de subir des inégalités en matière de soins de santé. Les données existantes révèlent que les étudiants en formation pour devenir des professionnels de la santé et leurs professeurs estiment que leurs programmes d'études actuels ne les préparent pas adéquatement à s'attaquer à ces inégalités. L'objectif de cette étude était d'identifier les obstacles qui entravent l'inclusion de contenu autochtone adéquat dans les programmes d'études de la formation des professionnels de la santé. Des entrevues semi-structurées ont été menées avec 33 membres du corps enseignant, issus de diverses disciplines de la santé, d'une université du Canada. Une analyse thématique a permis d'identifier quatre principaux obstacles : 1) le nombre insuffisant de professeurs autochtones et la surcharge de travail qui en résulte ; 2) la nécessité d'accroître la formation et la capacité des professeurs non autochtones ; 3) le manque de supervision et d'orientation concernant le contenu des programmes et les approches de formation ; et 4) le temps limité qui entraîne une concurrence 
de priorité des thèmes abordés. Il est nécessaire de surmonter ces obstacles pour préparer les étudiants à fournir des soins de santé sûrs et équitables aux Autochtones.

Mots-clés : santé des Autochtones, professionnels de la santé, programmes d'études, perspectives du corps enseignant, obstacles, Canada 


\section{Introduction}

Despite the unique responsibilities that Canada has to ensure the well-being of Indigenous peoples, certain Indigenous populations continue to experience the worst health and social outcomes in the country (First Nations Information Governance Centre, 2018; Inuit Tapiriit Kanatami, 2018; Statistics Canada, 2013). Inequities in the availability, accessibility, and provision of culturally competent and safe health care are in part responsible for the ongoing gaps in health outcomes between Indigenous and non-Indigenous peoples in Canada and elsewhere (Allan \& Smylie, 2015; Hole et al., 2015; Indigenous Health Working Group, 2016; Jull \& Giles, 2012; Matthews, 2017; Tang \& Browne, 2008; The Truth and Reconciliation Commission of Canada [TRC], 2015a; Vang et al., 2018). The final report of Truth and Reconciliation Commission (TRC) of Canada included various "Calls to Action" to reduce inequities, including a call to ensure that health profession students receive training that prepares them to provide culturally safe care for Indigenous peoples (TRC, 2015b). Universities in Canada have been trying to meet this directive; however, recent evidence suggests that several barriers continue to exist across institutions, limiting the ability to provide adequate curricular content related to Indigenous peoples that effectively prepares learners to provide equitable care to Indigenous peoples (Macdonald, 2016; Vogel, 2018).

\section{Training and Education to Improve Health Care for Indigenous Populations}

According to the 2016 Census, $4.9 \%$ of the Canadian population identified as Indigenous (Statistics Canada, 2017), yet only $2.2 \%$ of health care professionals identified as Indigenous that same year (Statistics Canada, 2017). Specific to medicine, a 2016 survey conducted at 10 out of the 17 Canadian medical schools at the time revealed that only $2.6 \%$ of new students were Indigenous (Sadler et al., 2017). This underrepresentation of Indigenous peoples in health care professions means that non-Indigenous providers deliver the majority of health care to Indigenous peoples (Shah \& Reeves, 2012). Although many providers are capable of providing culturally safe care to people from diverse backgrounds, the continued racism and inequities faced by Indigenous peoples suggest that significant improvement to health professional training is necessary to improve health 
care for Indigenous peoples (Allan \& Smylie, 2015; Kurek et al., 2016; Shen et al., 2018; Wylie \& McConkey, 2018). Recognizing the urgent need to improve health care for Indigenous peoples, various Indigenous and non-Indigenous organizations, health leaders, scholars, and health profession students have emphasized the need for mandatory training in order to improve the health status of Indigenous peoples (Berg et al., 2019; Canadian Federation of Medical Students, 2015; Greenwood et al., 2017; Health Council of Canada, 2011; Henderson \& Crowshoe, 2019; Shah \& Reeves, 2012). Considering the clear need for improved education for health care providers in relation to Indigenous peoples, it is problematic that many health profession programs provide little or no mandatory training in this regard (Henry, 2012; Paul et al., 2014; Vang et al., 2018).

Several studies have revealed that educating health care professionals about the unique needs of diverse groups can lead to improved knowledge, attitudes, skills, and behaviours that relate to the provision of culturally appropriate and equitable care (Clifford et al., 2015; Kurtz et al., 2018; Truong et al., 2014). For example, an evaluation of a three-hour educational intervention related to the health of Indigenous peoples for occupational therapy students at a Canadian university revealed improvements in perceived knowledge, non-judgemental views, open-mindedness, and a heightened interest in collaborating with and advocating for Indigenous peoples (Jamieson et al., 2017). Similarly, a three-hour seminar on Indigenous health for medical students at a Canadian university led to improvements in student knowledge about relevant topics, as well as increased perceived importance of Indigenous health content and willingness to work with Indigenous communities (Zhou et al., 2012). Following the training, students in both studies reported having a better understanding of how they could improve Indigenous health outcomes in their future work (Jamieson et al., 2017; Zhou et al., 2012).

Despite this research demonstrating certain beneficial attitudinal or behavioural changes as a result of educational interventions, it has been suggested that many health profession programs still do not adequately prepare students to deliver effective care to Indigenous peoples and diverse groups (Guerra \& Kurtz, 2016; Hart et al., 2015; Pauly et al., 2015). In this regard, $40 \%$ of family medicine residents at a Canadian university reported feeling underprepared to work in Indigenous contexts (Larson et al., 2011). A survey among Canadian obstetrics and gynaecology residents revealed they had little background knowledge and recognized the importance of receiving more education (Jumah et al., 2013). Further, it has been previously reported that health professions faculty 
at a Canadian university perceived the content in health profession programs to be inadequate in preparing students to deliver culturally safe care to Indigenous patients (Doria et al., 2018).

\section{Barriers to the Delivery of Effective Training in Health Professional Programs}

Although the importance of diversity and cultural training is increasingly being acknowledged in the literature, a number of barriers have been reported that prevent the implementation of training that adequately prepares students to provide adequate care for diverse groups (Betancourt \& Green, 2010; Guerra \& Kurtz, 2016; Macdonald, 2016). A 2010 review assessing key documents related to shaping medical school curricula for diverse groups in Canada, the United Kingdom, and the United States identified that key barriers included a lack of regulation from governing bodies and a lack of conceptual clarity for learning objectives and approaches (Dogra et al., 2010). Additional barriers in this review included the continued ambivalence among decision makers about the importance of content related to diversity for health professionals, and its low perceived priority in already overloaded curricula (Dogra et al., 2010).

Further, a province-wide cultural safety initiative offered in Ontario post-secondary institutions identified their biggest challenge as securing time in the already cramped curricula of health programs (Shah \& Reeves, 2012). Another article describing the development and delivery of curriculum related to Indigenous peoples at a medical school in Ontario described two challenges: first, the need to negotiate for time, and second, tensions related to devaluing Indigenous knowledge systems (Jacklin et al., 2014). A 2018 systematic review that specifically explored factors influencing the development of Indigenous content in health practitioner training identified the lack of capacity as a key barrier (Pitama et al., 2018). Similarly, the majority of clinical teachers in a New Zealand study reported feeling unprepared to deliver content related to Maori health (Jones et al., 2013), and an Australian study revealed that most health sciences faculty felt unsure or awkward when teaching Indigenous content (Wolfe et al., 2018). Likewise, general practitioner educators at a medical school in Australia reported feeling poorly qualified to teach Indigenous health and preferred that Indigenous educators deliver this content (Vass \& Adams, 2021). 
In order to better understand barriers that prevent the provision of curricular content related to Indigenous peoples in health professions programs, the current study explored the perspectives of health profession faculty at a Canadian university. Importantly, Indigenous, anti-colonial, and anti-racist frameworks call for the active dismantling of the structures that reinforce inequities, including those within educational and health care contexts (Allan \& Smylie, 2015; Hart, et al., 2017; Kovach, 2015; Sefa Dei, 2008). This study, and the discussion that follows, are grounded in these frameworks and aim to address anti-colonial practice in health care and health care education as a means of reconciliation, reducing inequities, and improving care for Indigenous peoples in Canada.

\section{Methods}

All faculty members listed on the websites of five health profession programs (medicine, nursing, dentistry, pharmacy, and social work) at a medium-sized Canadian university were invited to participate. A total of 33 faculty members were interviewed in 2018, representing all five invited programs (six social work, eight medicine, 12 nursing, five dentistry, two pharmacy). Interviewees included Indigenous and non-Indigenous faculty members who held a variety of positions, including deans, assistant deans, directors, professors, associate professors, and assistant professors. A diversity of ages, genders, and years of experience in academia and at the institution was represented. To protect the identity of those interviewed, demographic details are not provided. Ethics approval to conduct this research was granted by the institution's Research Ethics Board.

One-on-one semi-structured interviews were conducted using an interview guide inquiring about experiences and attitudes related to incorporating Indigenous content into curricula. Interviews lasted between 45 and 90 minutes, and were audio-recorded, transcribed verbatim, and then analyzed using thematic analysis (Braun \& Clarke, 2006). Guided by Braun and Clarke (2006), members of the research team independently coded 10 transcripts to become familiar with the data. The team then met to compile a list of initial codes. Each of the transcripts were then independently coded by two of the authors using NVivo 12 (QSR International, Melbourne). The original 10 transcripts used for the generation of codes were re-coded for consistency. The analysis process was iterative, with additional codes added to the framework as needed if agreed upon by all coders 
(Braun \& Clarke, 2006). The coded transcripts were reviewed by a third team member, and discrepancies were reconciled in consultation with the initial two coders. Codes were then collated into themes, which were refined and agreed upon by the entire research team (Braun \& Clarke, 2006).

\section{Findings}

Participants detailed their experiences and perspectives related to the development and delivery of effective Indigenous content into health profession curricula, with each participant describing barriers and challenges that exist to doing so. Four main barriers were identified: (1) limited number of Indigenous faculty, (2) the need for non-Indigenous faculty training and capacity, (3) lack of oversight and direction regarding curricular content and training approaches, and (4) the limited amount of time in curriculum and competing priorities.

\section{Limited Number of Indigenous Faculty: Underrepresented and Overburdened}

The majority of participants described the lack of Indigenous faculty members employed at the university as a substantial barrier to incorporating Indigenous content into curricula. The lack of Indigenous faculty was described as "a huge shortage" (P5), and most participants agreed that more Indigenous faculty needed to be hired.

Participants largely agreed that current Indigenous faculty were overburdened, stressed, and placed under extreme pressures. One participant commented, "We have very few Indigenous scholars on campus and so they're actually asked to do everything and so they're spread pretty thin" (P2). Given the lack of Indigenous representation across programs, the few Indigenous faculty members at the institution shoulder the burden of educating on Indigenous issues and achieving any deliverables that are Indigenous- or diversity-related. In recognition of the substantial burden placed on Indigenous faculty members beyond their own teaching and research requirements, another participant echoed, "We can't continue to ask them [our Indigenous faculty] to be everywhere in all places" (P24). 
Just as non-Indigenous faculty members recognized the challenges faced by Indigenous faculty, Indigenous faculty themselves reported feeling overwhelmed by the responsibilities of representing the Indigenous perspective in so many different contexts. An Indigenous faculty member described their own experience of being overburdened:

A lot of pressure gets put on the few faculty who have the expertise and so they kind of have additional workloads without a release of other things... one of the barriers we are seeing is the lack of capacity and always relying on the same people to do it. (P10)

In addition to their job requirements, Indigenous faculty are often asked to deliver Indigenous content through ad hoc guest lectures for various health profession courses and across the university. This burden was described to have increased in response to greater pressures to incorporate Indigenous health content into curricula. Participants reported having discussions within their faculties about implementing mandatory hours of Indigenous content to increase the time in each program. However, given the lack of faculty with expertise in this area, many believed this was not a solution at this time: "If you just increase the hours that we have right now, like we could but we can't because we don't have the expertise in the faculty to create more hours of curriculum and run more hours of curriculum" (P5). A preferred solution proposed by a number of participants was instead to hire more Indigenous scholars: "This is a universal problem...we have very few Indigenous scholars on campus... so it's finding a way to get first voice involved that doesn't completely exhaust their capacity. And one way is by creating new scholars" (P2).

Some participants expressed concern with both Indigenous and non-Indigenous students seeing a lack of Indigenous faculty in their health professional programs. In particular, there was worry that Indigenous students will not be able to see themselves as having a place in the health professions without Indigenous faculty present. One participant commented, "You know it makes a difference when a student comes in and sees the reflection of themselves in the staff and faculty" (P4). Similarly, another faculty member commented, "I mean whenever we can see ourselves in a profession, it's much more attractive to take or to pursue" (P8).

There was also concern that, without Indigenous faculty, Indigenous and non-Indigenous students would not trust the legitimacy of the Indigenous health curricula 
delivered: "If we don't have the role models in practice, it's difficult for students to see how we are actually providing that culturally safe and culturally competent health care. That's a challenge" (P26).

\section{Non-Indigenous Faculty: Cautious Allies in Need of Training and Capacity}

Although participants agreed that more Indigenous faculty was needed, some expressed that there was room for non-Indigenous faculty to increase their engagement in the process of improving Indigenous health curricula through allyship: "Non-Indigenous faculty need to be mindful of overburdening Indigenous faculty with this process and I think that there's space for allies and for people to assert themselves as such and to be available" (P22). Participants, however, largely reported that they were not adequately trained to develop and deliver Indigenous health content, and needed further education to do so.

We have not had faculty development in increasing our own awareness, you know? So how can you teach something you haven't experienced, or you discussed or are aware of, and yeah so, the faculty need orientation to teach this. (P33)

Some believed that incoming students were more educated than current faculty on the subject of Indigenous health:

It's just a matter of actually educating faculty, right? Because how can you know what's coming? You know the first-year students right now probably know more than most faculty about colonial history, and systemic racism, and social determinants of health impacting Indigenous people than their faculty members do. (P2)

Interviewees largely agreed that they did not have the knowledge and training to deliver Indigenous health content, but were eager to improve:

I think the faculty are keen to know more and that's one of the challenges is the faculty are also at a disadvantage in terms of their knowledge. They're the first ones to say like, we don't know this stuff but we know we need to know it. So that's why, you know, we're sort of in this situation now. (P23) 
Many believed that further training would make faculty "more comfortable" (P21) and that faculty were in need of this development. Numerous participants echoed the need for professional development to go beyond improving professors' knowledge bases, and to include instruction on mechanisms for appropriate content delivery. Due to a lack of knowledge and formal training, several participants expressed concerns about unintentionally perpetuating inaccurate information and stereotypes and how this could cause further harm:

I worry about articulating a homogenous account of things. It is not $-\mathrm{I}$ am not Indigenous and so I worry sometimes...I don't want to re-traumatize people. I don't want to assume that people don't know these histories intimately because of course people do. (P22)

In fear of perpetuating stereotypes, some participants felt it would be better not to deliver Indigenous content in health professions programs at all, rather than to do it poorly:

I think sometimes rather than do something very badly and being in a situation where we don't have the collaborators we need, the default is let's not make things bad, but the downside is we don't do anything at all. (P28)

This fear resulted in the majority of participants choosing not to deliver Indigenous content in the courses or training they had developed or delivered themselves.

Some faculty members also described how making changes to develop and deliver adequate curriculum was hindered by the attitudes of some non-Indigenous faculty member who were not particularly supportive or interested:

There will be people who are just not interested; they're not interested-I'm interested in cultural racism... They're not trained that way. There are people who will say this is creating more work for me. So systemically, there will be resistance of people who are not trained, people who think it's more work, who don't want to do it. (P31)

At the same time, another participant commented: "We've got a lot of work to do but there definitely is the commitment here and there definitely is the commitment across the faculty...commitment to do better than what we're doing" (P24). 


\section{Lack of Oversight and Direction for the Implementation of Indigenous Content}

Participants also believed that there was a lack of direction when it came to developing health profession curricula related to Indigenous peoples. Interviewees described how there were no requirements or instruction provided to them on the specific content to be included, nor was support provided to develop, deliver, or evaluate content. Participants reported that decisions regarding the specific content to include are often left to individual faculty members to incorporate as they choose, based on their own interests and expertise. This lack of direction and oversight left many feeling overwhelmed, and "helter skelter" (P6), without a clear understanding of who to look to for guidance: "There's all sorts of different things we could do, but it all comes down to someone organizing it to make it happen, and to support it" (P10).

The lack of procedure or framework for content inclusion was reported to impede participants' abilities to affect change, even if they are keen to do so. One participant commented:

You have to put the structures in place and you have to have people designated that maybe start building these relationships, because if you again leave it up to individual course professors then it really needs to be something that's all very clear about what is required. (P26)

Without direction, participants reported that incorporating Indigenous content into curricula proved challenging, causing current attempts to be inadequate and inconsistent.

Participants also noted a lack of clear direction as to how much time to allocate to Indigenous-related curricula. Beyond requiring the general inclusion of some type of Indigenous content, many participants discussed how mandating minimum specific content requirements could provide direction and formality to the process:

I think if you impose a requirement then that means that people are required to incorporate Aboriginal content into their curriculum... I don't know what would be required but I think something has to be done through the faculty a little bit more, systemically, to mandate the inclusion of Aboriginal issues within the schools... if you leave it the way it is now, then there's always going to be the argument by some professors, “it doesn't fit here.” (P31) 
Other participants echoed the benefit of formalized requirements for incorporating Indigenous content into curricula:

If you want something to be systematic, we need to have some sort of formality. Too bad we have to get to that way, but it is perhaps one way, in order to ensure that no matter what course students are taking they get that exposure. (P21)

In contrast, some participants were uncertain about the effectiveness of implementing minimum or mandatory time requirements, but believed it could be a start that led to other needed changes:

One is don't just impose a minimum...that's going to result in really low-quality classroom-based experiences. But it can sometimes be politically effective to impose a minimum and then the school turns around and says well how can we possibly meet that minimum and then you say oh I guess we have to actually develop clinical service delivery and hire faculty in this area. (P5)

Although some participants were uncertain about mandating curriculum, they agreed that some form of clear direction was needed, coming from the faculty level or higher.

Finally, the lack of formal program evaluation was also discussed as a barrier to implementing adequate and sustainable Indigenous curricula: "I think that there needs to be an evaluative process because unless in some ways it's tracked to see if the benchmark is being met and feedback given, positive or not so positive, it loses its sustainability" (P30). Similarly, another participant commented:

Evaluation, ongoing monitoring around this is incredibly important.... How do we know when we're getting it right? How do we know when the way that we're grading students is meaningful, to all of us? How do we know as faculty and staff when we're going through tenure and rigor of tenure and promotion, how do we know when we have the criteria right? How do we catch when we're getting it wrong? (P24)

Participants felt that incorporating evaluation into content delivery was an important part of providing much needed future direction that would enable and empower faculty to incorporate Indigenous content into curricula. 


\section{Zero-Sum Game: Not Enough Time in Curriculum and Competing Priorities}

Participants often spoke to the difficulty of securing agreement from all necessary parties to add various aspects of cultural training to an already-full curricula. Some commented that prioritizing Indigenous health content meant that there would be fewer hours to discuss other important topics. New "competing demands" (P28) were described to impede the inclusion of Indigenous health content, and the gain of Indigenous curricula would result in the inability to include curricula on other necessary topics or populations.

To be honest like you can't make everything Indigenous either. There are other things too. We tried to do transgender stuff and different sexualities are not common. Students need to deal with [other things too]. So, you kind of have to have that diversity lens. There can't be all of one thing and then none of the others. (P6)

The competing demands of addressing diverse experiences in health care were reported by multiple participants. Another participant similarly commented: "If I'm respecting what the TRC is asking for and I'm putting energy and effort around Indigenizing the curriculum and the school, am I in any way taking away from students with disability issues or African [Canadian] issues?" (P4). Many participants described the need to achieve the implementation of adequate Indigenous curriculum effectively "without losing what else is crucial" (P28). This created a constant struggle for some, leaving them asking "where do we put our emphasis" (P32) because "it's difficult to just put an emphasis on Indigenous health" (P27).

Given that some faculty members were reported as having their own ties or commitments to other specific diversity issues, incorporating Indigenous content into curricula was reported by some to have created "pressure from other people fighting for more time for other things that are considered more valuable or important" (P10). One participant highlighted how the different "special interests" of faculty could create tensions:

The problem is there's too many people with special interests. Because as soon as you say we're going to do all this Indigenous stuff, then, and this sounds terrible but it's the reality...the African [Canadian] group or a Muslim group or maybe it's a religious group...so you get into all this political sort of thing with special 
interests... so you do need to be careful about representing or over representing a particular population and the lens you present it with. (P6)

Finally, participants identified difficulties with incorporating sufficient Indigenous health material when there were already constraints for time to deliver the current material. Time, here, was often given as "the ultimate barrier" (P10). Many participants felt that time constraints were a key barrier to the current content being inadequate: "I think everything is varied, everything becomes - a lot from time restraint — very generic and not terribly specific" (P18). As a result, the inclusion of Indigenous-related content is often superficial, and its delivery was described to be insufficient by many because of the limited time allotted:

With only 2 hours of lecture you are only really able to cover some of the history that is necessary to cover Indigenous health issues. Currently, the way it is, we don't have a lot of time to delve into all of the ways this impacts health, all of the ways this impacts health care. (P10)

With so little time devoted to Indigenous health issues and competing needs to include core content and content related to other social groups, it was agreed upon by most participants that it was difficult "to address what is very complicated" (P25).

\section{Discussion}

The faculty who participated in this study generally felt that many people at the institution strongly supported working toward equity and improved health care for Indigenous peoples. Nevertheless, participants noted significant barriers that must be overcome in order to ensure that students who are graduating from health profession programs feel prepared to provide culturally safe care to Indigenous peoples when they enter the workforce. Consistent with findings from other countries (Virdun et al., 2013), the limited number of Indigenous faculty in the health professions was identified as a key obstacle to implementing adequate and effective Indigenous curricular content. Participants noted that Indigenous professors who are currently at the institution are often overburdened and at risk for burnout. Similar findings have been described in other studies exploring experiences of Indigenous faculty members in Canada (Battiste et al., 2002; Henry, 
2012; Henry et al., 2017; Mohamed \& Beagan, 2019). This has also been recognized as problematic by the Canadian Association of University Teachers (2015), who issued the following policy statement:

Academic staff who are also members of equity-seeking groups are frequently called upon to perform extra duties, such as interpreting documents through an “equity lens,"... Requests for additional work come not only from a variety of administrative and departmental sources, but also from academic staff associations. Such work receives little official recognition and adds an unfair burden to the workload of members of equity-seeking groups, thus creating another equity problem.

Compounding the need for more Indigenous faculty, participants also described that many non-Indigenous faculty did not have the adequate knowledge or training related to the health of Indigenous peoples or the history of colonialism in Canada. These experiences are similar to what has been reported by faculty members in Australia, where many felt discomfort in delivering Indigenous-related content for various reasons such as being worried they would make mistakes, not knowing what to teach, and finding it "too hard" (Williamson \& Dalal, 2007; Wolfe et al., 2018). Some faculty in the current study also expressed worry that if they were forced to include Indigenous content without having the adequate knowledge or support that they may accidently perpetuate stereotypes or incorporate the content in a harmful way. This worry is not unfounded, as Indigenous students have reported discriminatory practices and a lack of cultural sensitivity when being taught about Indigenous culture by non-Indigenous academics in other contexts (Kippen et al., 2006; Turale \& Miller, 2006; West et al., 2010).

Most adults in Canada - including university professors and health care professionals - have not received adequate education in relation to the health of Indigenous peoples throughout their high school, post-secondary, and/or professional education (TRC, 2015a). In turn, it is unsurprising that many do not know some of the basics in relation to our collective history of colonialism and the unique determinants of health that affect Indigenous peoples (Angus Reid Institute, 2018; Environics Institute, 2016, 2019). Interviews with faculty at a medical school in Canada revealed that none had received any formal training regarding Indigenous heath, with some expressing common inaccurate beliefs that discounted the unique determinants of health affecting Indigenous 
peoples (Sylvestre et al., 2019). In the current study, a significant number of faculty members acknowledged the need for themselves and/or colleagues to improve their knowledge related to Indigenous peoples, with some suggesting the need for faculty training to be made available or mandatory. This appears to be the case in other contexts in Canada as well. For example, a number of health care providers at a hospital in Ontario recognized their lack of knowledge related to Indigenous people's health and expressed interest in receiving training (Wylie \& McConkey, 2018).

Although most interviewees expressed their personal support for necessary changes to improve the curriculum, there was some concern that other faculty members did not see the importance. Further, some participants expressed ambivalence around their own personal attitudes and/or questioned the importance of prioritizing Indigenous content within the allotted time. Several participants emphasized that they were operating within a zero-sum environment for adapting health profession curricula and that any additional time devoted to Indigenous health meant time taken away from content related to other diverse groups or what is considered to be traditional core curricula (e.g., anatomy, physiology). This was also described by a faculty member at another university in Canada who explained it was necessary to "convince" colleagues that Indigenous health content was important, as it was sometimes viewed as "nice to know" but not "need to know" (Beavis et al., 2015). Likewise, a study in Australia reported that faculty members questioned the relevance of Indigenous content and raised concerns about an already full curriculum (Roberts et al., 2010). Academic institutions need to nurture a more holistic and intersectional approach to incorporating Indigenous health content, instead of viewing it as a zero-sum game. Viewing Indigenous health content from a zero-sum approach displays an ethos of unexamined colonial racist privilege that prevents Indigenous health curricula from being prioritized.

This notion of competing priorities and the narrative that there are too many "special needs" to be met can be destructive, as it might propagate the attitude that the needs of marginalized and minority groups are supplemental and only in addition to the health care needs of the majority. Equating Indigenous peoples with other social groups in Canada also erases their specific and unique position as the Indigenous peoples of this land. This denies the current reality in which treaties and rights are not upheld and Indigenous peoples face the greatest inequities in the country (Allan \& Smylie, 2015; St. Denis, 2011; McNally \& Martin, 2017). A poll in 2018 revealed that just over half (53\%) 
of Canadians felt that "Indigenous peoples should have no special status that other Canadians don't have" (Angus Reid Institute, 2018; p. 1). Likewise, just under half (48\%) of non-Indigenous Canadians surveyed in 2019, thought that "Indigenous peoples are just like other cultural or ethnic groups [in Canada]" (Environics Institute, 2019, p. 9).

Many scholars have argued for the need to "unsettle" assumptions that Indigenous peoples represent one of many equity-seeking groups, and for individuals and institutions to move beyond multicultural frameworks to those focused on recognizing the unique status of Indigenous peoples (Allan \& Smylie, 2015; Battiste \& Youngblood Henderson, 2012; McGibbon et al., 2014; McNally \& Martin, 2017; Pelak, 2019; Robertson, 2015; Steinman, 2016; St. Denis, 2011). This is not to say that race-based and intersectional frameworks are not important and essential to include in health profession curricula, but instead to emphasize that they are not sufficient to prepare health care providers to address the unique needs of Indigenous peoples.

Faculty members in this study also highlighted the lack of oversight and guidance related to curricular content as another significant barrier. Some faculty described the existing attempts to encourage the integration of Indigenous content in curricula as being comprised of mandating minimum content hours for certain courses, but didn't have clearly outlined priorities and objectives. This lack of guidance made the process of incorporating Indigenous content extremely challenging for most, especially for those who reported not being adequately prepared. Several faculty participants identified the need for dedicated people to lead the ongoing oversight and evaluation of incorporated Indigenous content. This barrier has also been suggested in relation to cultural competence and safety training, with scholars recommending that several procedures are needed to ensure improvements are being made (Sorensen et al., 2017). Some participants, however, also cautioned that mandating formalized requirements would not be feasible until dedicated people with the necessary expertise, time, and resources to oversee the process effectively were in place. There also appears to be a lack of direction from health professional bodies about the best way to prepare students to provide care for Indigenous and diverse groups. An exception in Canada is the First Nations, Inuit, Métis Health Core Competencies, which outlines an Indigenous health curriculum framework for undergraduate medical education (Indigenous Physicians Association of Canada, 2009). This framework provides guidance for faculty members who are developing content. However, further 
support is needed from decision makers and administration at each institution and within each program to implement the outlined objectives effectively.

Despite the insufficient number of Indigenous faculty at the institution at the time of the interviews, participants generally agreed that the oversight and implementation of Indigenous health content should be informed and directed by Indigenous voices and supported by allies with the appropriate expertise. This is consistent with research in other countries and contexts highlighting the importance of Indigenous faculty and leadership as key drivers to implementing Indigenous health curricula (Pitama et al., 2018). It is clear that one key component of the solution is to hire more Indigenous faculty and non-Indigenous faculty with the appropriate expertise and/or experience. Until this is achieved at various institutions across Canada, the limited number of experienced faculty may be better utilized in providing oversight and guidance in the development and delivery of content. As described by other medical schools in Canada, Indigenous knowledge holders, Elders, and others who do not have a typical academic background can work with faculty members to co-develop and deliver Indigenous content (Strasser et al., 2009). Since our interviews took place, faculty members at this university have worked in partnership with local Indigenous health leaders and knowledge holders to develop and pilot an introductory course related to Indigenous groups that is mandatory for certain groups of first-year health professional students.

\section{Conclusion}

It should be noted that faculty members who were interviewed in the current study were self-selected and may have been more likely to prioritize and value issues related to Indigenous health and/or to diversity and equity. Our analysis also did not consider differences across programs in relation to capacity, curriculum content, and/or delivery and, therefore, differences may exist between programs that were not considered. Although financial barriers were not a major topic described by participants, the solutions to address the barriers that were identified will inevitably require sustained financial commitments; future research should explore the extent to which financial barriers impact the provision of adequate curricular content related to Indigenous peoples in health professions. Despite these limitations, the current study adds to the literature by exploring 
factors that continue to influence delivery of Indigenous content in health profession curricula in Canada. Further, although participants may have been more likely to prioritize and value issues related to Indigenous health and/or diversity and equity, it is simultaneously true that academia is an environment that has historically ignored Indigeneity, and it was evident that internalized bias, resistance, and/or discomfort with Indigenous content remained present among self-selected participants.

Faculty members in this study identified several barriers to the implementation of adequate content related to Indigenous peoples in health profession curricula. These barriers result in health profession students receiving inadequate training and, therefore, health professionals are often ill equipped to provide sufficient care for Indigenous peoples. Universities must prioritize reducing the health inequities of Indigenous peoples given their unique status in Canada and the historical context of colonization. The full support of institutions is necessary for meaningful change to occur, and universities have an obligation to devote the necessary resources to do so. Overall, improving health profession curricula is a key component to reducing the inequities experienced by Indigenous peoples in Canada. 


\section{References}

Allan, B., \& Smylie, J. (2015). First Peoples, second class treatment: The role of racism in the health and wellbeing of Indigenous peoples in Canada. Wellesley Institute.

Angus Reid Institute. (2018). Truths of reconciliation: Canadians are deeply divided on how best to address Indigenous issues. http://angusreid.org/wp-content/ uploads/2018/06/2018.04.23 indigenous fullreport.pdf

Battiste, M., Bell, L., \& Findlay, L. M. (2002). Decolonizing education in Canadian universities: An interdisciplinary, international, Indigenous research project. Canadian Journal of Native Education, 26(2), 82.

Battiste, M., \& Youngblood Henderson, S. (2012). Oppression and the health of Indigenous peoples. In E. McGibbon (Ed.), Oppression: A social determinant of health (pp. 89-96). Fernwood Publishing.

Beavis, A. S. W., Hojjati, A., Kassam, A., Choudhury, D., Fraser, M., Masching, R., \& Nixon, S. A. (2015). What all students in healthcare training programs should learn to increase health equity: Perspectives on postcolonialism and the health of Aboriginal peoples in Canada. BMC Medical Education, 15, 155.

Berg, K., McLane, P., Eshkakogan, N., Mantha, J., Lee, T., Crowshoe, C., \& Phillips, A. (2019). Perspectives on Indigenous cultural competency and safety in Canadian hospital emergency departments: A scoping review. International Emergency Nursing, 43, 133-140.

Betancourt, J. R., \& Green, A. R. (2010). Commentary: Linking cultural competence training to improved health outcomes: perspectives from the field. Academic Medicine, 85(4), 582-586.

Braun, V., \& Clarke, V. (2006). Using thematic analysis in psychology. Qualitative Research in Psychology, 3(2), 77-101. https://doi. org/10.1191/1478088706qp063oa

Canadian Association of University Teachers. (2015). Recognition of increased workload of academic staff members in equity-seeking groups in a minority context. https://www.caut.ca/about-us/caut-policy/lists/caut-policy-statements/ 
recognition-of-increased-workload-of-academic-staff-members-in-equity-seekinggroups-in-a-minority-context

Canadian Federation of Medical Students. (2015). Indigenous peoples in health in Canadian medical education: CFMS position paper. https://www.cfms.org/files/ position-papers/2015 indigenous_people_in_canadian_med_ed.pdf

Clifford, A., McCalman, J., Bainbridge, R., \& Tsey, K. (2015). Interventions to improve cultural competency in health care for Indigenous peoples of Australia, New Zealand, Canada and the USA: A systematic review. International Journal for Quality in Health Care, 27(2), 89-98.

Dogra, N., Reitmanova, S., \& Carter-Pokras, O. (2010). Teaching cultural diversity: Current status in U.K., U.S., and Canadian medical schools. Journal of General Internal Medicine, 25(2), 164-168.

Doria, N., Biderman, M., Boudreau, J., Sinno, J., Mackley, M., \& Bombay, A. (2018, May 28-31). Effectiveness of current curricula in adequately preparing Dalhousie University health professional students to work with Indigenous peoples [Poster presentation]. Canadian Association for Health Services and Policy Research (CAHSPR) Conference, Montreal, QC, Canada.

Environics Institute. (2016). Canadian public opinion on Aboriginal peoples: Final report. https://www.environicsinstitute.org/docs/default-source/projectdocuments/public-opinion-about-aboriginal-issues-in-canada-2016/final-report. pdf?sfvrsn $=30587 \mathrm{aca} 2$

Environics Institute. (2019). 2019 survey of Canadians: Toward reconciliation: Indigenous and non-Indigenous perspectives: Final report. https://www. environicsinstitute.org/docs/default-source/default-document-library/3rdconfed-survey-report-final-oct8409422a163c841928b54f1d5bfbaa24e. pdf?sfvrsn $=\mathrm{c} 731 \mathrm{~d} 090 \quad 0$

First Nations Information Governance Centre. (2018). National report of The First Nations Regional Health Survey; Phase 3: Volume two. https://nigc.ca/ wp-content/uploads/2020/09/53b9881f96fc02e9352f7cc8b0914d7a_FNIGC RHS-Phase-3-Volume-Two EN_FINAL_Screen.pdf 
Greenwood, M., Lindsay, N., King, J., \& Loewen, D. (2017). Ethical spaces and places: Indigenous cultural safety in British Columbia health care. AlterNative, 13(3), 179-189.

Guerra, O., \& Kurtz, D. (2016). Building collaboration: A scoping review of cultural competency and safety education and training for healthcare students and professionals in Canada. Teaching and Learning in Medicine, 29(2), 129-142. https://doi.org/10.1080/10401334.2016.1234960

Hart, B., Cavanagh, M., \& Douglas, D. (2015). The "strengthening nursing culture project" - an exploratory evaluation study of nursing students' placements within Aboriginal medical services. Contemporary Nurse, 51(2-3), 245-256.

Hart, M. A., Straka, S., \& Rowe, G. (2017). Working across contexts: Practical considerations of doing Indigenist/anti-colonial research. Qualitative Inquiry, 23(5), 332-342.

Health Council of Canada. (2011). Understanding and improving Aboriginal maternal and child health in Canada: Conversations about promising practices across Canada. https://publications.gc.ca/collections/collection_2011/ccs-hcc/H174-232011-eng.pdf

Henderson, R. I., \& Crowshoe, L. L. (2019). Confronting healthcare implications of racism for Indigenous peoples. https://acfp.ca/wp-content/uploads/2019/03/ SAT 1030 2F_Racism_IndigenousHealth_Henderson-Crowshoe.pdf

Henry, F. (2012). Indigenous faculty at Canadian universities: Their stories. Canadian Ethic Studies, 44(2), 101-132.

Henry, F., Dua, E., Kobayashi, A., James, C., Li, P., Ramos, H., \& Smith, M. S. (2017). Race, racialization and Indigeneity in Canadian universities. Race Ethnicity and Education, 20(3), 300-314. https://doi.org/10.1080/13613324.2016.1260226

Hole, R. D., Evans, M., Berg, L. D., Bottorff, J. L., Dingwall, C., Alexis, C., Nyberg, J., \& Smith, M. L. (2015). Visibility and voice: Aboriginal people experience culturally safe and unsafe health care. Qualitative Health Research, 25(12), $1662-1674$.

Indigenous Health Working Group. (2016). Health and health care implications of systemic racism on Indigenous Peoples in Canada: Indigenous Health Working 
Group: Fact sheet. https://portal.cfpc.ca/ResourcesDocs/uploadedFiles/ Resources/_PDFs/SystemicRacism_ENG.pdf

Indigenous Physicians Association of Canada. (2009). Core competencies: A curriculum framework for continuing medical education. https://www.hhr-rhs.ca/index. php?option $=$ com_mtree\&task $=$ att_download\&link_id=10851\&cf_id=68\&lang $=$ en

Inuit Tapiriit Kanatami. (2018). Inuit statistical profile 2018. https://www.itk.ca/ wp-content/uploads/2018/08/Inuit-Statistical-Profile.pdf

Jacklin, K., Strasser, R., \& Peltier, I. (2014). From the community to the classroom: The Aboriginal health curriculum at the Northern Ontario School of Medicine. Canadian Journal of Rural Medicine, 19, 143-150.

Jamieson, M., Chen, S. P., Murphy, S., Maracle, L., \& Mofina, A. (2017). Pilot testing an intervention on cultural safety and Indigenous health in a Canadian occupational therapy curriculum. Journal of Allied Health, 46(1), E1-E7.

Jones, R., Henning, M. A., Pinnock, R., Shulruf, B., \& Hawken, S. J. (2013). Medical students' and clinical teachers' perceptions of Māori health teaching. New Zealand Medical Journal, 126, 1377.

Jull, J., \& Giles, A. (2012). Health equity, Aboriginal peoples and occupational therapy. Canadian Journal of Occupational Therapy, 79(2), 70-76.

Jumah, N. A., Wilson, D., \& Shah, R. (2013). A Canadian survey of postgraduate education in Aboriginal women's health in obstetrics and gynaecology. Journal of Obstetrics and Gynaecology Canada, 35(7), 647-653.

Kippen, S., Ward, B., \& Warren, L. (2006). Enhancing Indigenous participation in higher education health courses in rural Victoria. The Australian Journal of Indigenous Education, 35, 1-10.

Kovach, M. (2015). Emerging from the margins: Indigenous methodologies. In L. Brown \& S. Strega (Eds.), Research as resistance: Revisiting critical, Indigenous, and anti-oppressive approaches (2nd ed., pp 43-64). Women's Press, Canadian Scholars.

Kurek, K., Teevan, B. E., Zlateva, I., \& Anderson, D. R. (2016). Patient-provider social concordance and health outcomes in patients with type 2 diabetes: A retrospective 
study from a large federally qualified health center in Connecticut. Journal of Racial and Ethnic Health Disparities, 3(2), 217-224.

Kurtz, D. L. M., Janke, R., Vinek, J., Wells, T., Hutchinson, P., \& Froste, A. (2018). Health sciences cultural safety education in Australia, Canada, New Zealand and the United States: A literature review. International Journal of Medical Education, 9, 271-285.

Larson, B., Herx, L., Williansom, T., \& Crowshoe, L. (2011). Beyond the barriers: Family medicine residents' attitudes towards providing Aboriginal health care. Medical Education, 45(4), 400-406.

Macdonald, M. (2016, April 6). Indigenizing the academy. University Affairs. https:// www.universityaffairs.ca/features/feature-article/indigenizing-the-academy/

Matthews, R. (2017). The cultural erosion of Indigenous people in health care. CMAJ, 16(168), E78-79.

McGibbon, E., Mulaudzi, F. M., Didham, P., Barton, S., \& Sochan, A. (2014). Toward decolonizing nursing: The colonization of nursing and strategies for increasing the counter-narrative. Nursing Inquiry, 21(3), 179-191.

McNally, M., \& Martin, D. (2017). First Nations, Inuit and Metis health: Considerations for Canadian health leaders in the wake of the Truth and Reconciliation Commission of Canada report. Healthcare Management Forum, 30(2), 117-122.

Mohamed, T., \& Beagan, B. L. (2019). 'Strange faces' in the academy: Experiences of racialized and Indigenous faculty in Canadian universities. Race Ethnicity and Education, 22(3), 338-354.

Paul, D., Ewen, S. C., Jones., R. (2014). Cultural competence in medical education: Aligning the formal, informal and hidden curricula. Advances in Health Sciences Education: Theory and Practice, 19, 751-758.

Pauly, B., McCall., J., Browne, A., Parker, J., \& Mollison, A. (2015). Toward cultural safety - Nurse and patient perceptions of illicit substance abuse in a hospitalized setting. Advances in Nursing Science, 38(2), 121-135. 
Pelak, C. F. (2019). Teaching and learning about settler-colonial racism: A case for 'unsettling' minoritizing and multicultural perspectives. Sociology of Race and Ethnicity, 5(2), 294-304.

Pitama, S. G., Palmer, S. C., Huria, T., Lacey, C., \& Wilkinson, T. (2018). Implementation and impact of indigenous health curricula: A systematic review. Medical Education, 52(9), 898-909.

Roberts, J., Sanders, T., Mann, K., \& Wass, V. (2010). Institutional marginalisation and student resistance: Barriers to learning about culture, race and ethnicity. Advances in Health Sciences Education, 15(4), 559-571.

Robertson, D. L. (2015). Invisibility in the color-blind era: Examining legitimized racism against Indigenous peoples. American Indian Quaterly, 39(2), 113-153.

Sadler, K., Johnson, M., Brunette, C., Gula, L., Kennard, M., Charland, D., Tithecott, G., Cooper, G., Rieder, M., Watling, C., Herbert, C. P., Garcia, B., \& Hammond, R. R. (2017). Indigenous student matriculation into medical school: Policy and progress. The International Indigenous Policy Journal, 8(1).

Sefa Dei, G. J. (2008). Indigenous knowledge studies and the next generation: Pedagogical possibilities for anti-colonial education. The Australian Journal of Indigenous Education, 37(S1), 5-13.

Shah, C., \& Reeves, A. (2012). Increasing Aboriginal cultural safety among health care practitioners. Canadian Journal of Public Health, 103(5), 397.

Shen, M. J., Peterson, E. B., Costas-Muñiz, R., Hernandez, M. H., Jewell, S. T., Matsoukas, K., \& Bylund, C. L. (2018). The effects of race and racial concordance on patient-physician communication: A systematic review of the literature. Journal of Racial and Ethnic Health Disparities, 5(1), 117-140.

Sorensen, J., Norredam, M., Dogra, N., Essink-Bot, M. L., Suurmond, J., \& Krasnik, A. (2017). Enhancing cultural competence in medical education. International Journal of Medical Education, 8, 28.

St. Denis, V. (2011). Silencing Aboriginal curricular content and perspectives through multiculturalism: "There are other children here." The Review of Education, Pedagogy, and Cultural Studies, 33(4), 306-317. 
Statistics Canada. (2013). Select health indicators of First Nations people living off reserve, Metis and Inuit. Health at a Glance, 82-624-X. https://www150.statcan. gc.ca/n1/pub/82-624-x/2013001/article/11763-eng.htm

Statistics Canada. (2017). 2016 Census topic: Aboriginal peoples. https://www12.statcan. gc.ca/census-recensement/2016/rt-td/ap-pa-eng.cfm

Steinman, E. W. (2016). Decolonization not inclusion: Indigenous resistance to American settler colonialism. Sociology of Race and Ethnicity, 2(2), 219-236.

Strasser, R. P., Lanphear, J. H., McCready, W. G., Topps, W. G., Hunt, D. D., \& Matte, M. C. (2009). Canada's new medical school: The Northern Ontario School of Medicine: Social accountability through distributed community engagement learning. Academic Medicine, 84(10), 1459-1464.

Sylvestre, P., Castleden, H., Denis, J., Martin, D., \& Bombay, A. (2019). The tools at their fingertips: How settler colonial geographies shape medical educators' strategies for grappling with anti-Indigenous racism. Social Science \& Medicine, 237, 112363. https://doi.org/10.1016/j.socscimed.2019.112363

Tang, S. Y., \& Browne, A. J. (2008). 'Race' matters: Racialization and egalitarian discourses involving Aboriginal people in the Canadian health care context. Ethnicity and Health, 13(2), 109-127.

The Truth and Reconciliation Commission of Canada. (2015a). Honouring the truth, reconciling for the future: Summary of the final report of the Truth and Reconciliation Commission of Canada. http://nctr.ca/assets/reports/Final\%20 Reports/Executive_Summary_English_Web.pdf

The Truth and Reconciliation Commission of Canada. (2015b). Truth and Reconciliation Commission of Canada: Calls to action. http://www.trc.ca/websites/trcinstitution/ File/2015/Findings/Calls to Action_English2.pdf

Truong, M., Paradies, Y., \& Priest, N. (2014). Interventions to improve cultural competency in healthcare: A systematic review of reviews. BMC Health Services Research, 14, 99.

Turale, S., \& Miller, M. (2006). Improving the health of Indigenous Australians: Reforms in nursing education. An opinion piece of international interest. International Nursing Review, 53(3), 171-177. 
Vang, Z. M., Gagnon, R., Lee., T., Jimenez, V., Navickas, A., Pelletier, J., \& Shenker, H. (2018). Interactions between Indigenous women awaiting childbirth away from home and their southern, non-Indigenous health care providers. Qualitative Health Research, 28(12), 1858-1870.

Vass, A., \& Adams, K. (2021). Educator perceptions on teaching Indigenous health: Racism, privilege and self-reflexivity. Medical Education, 55, 213-221.

Virdun, C., Gray, J., Sherwood, J., Power, T., Phillips, A., Parker, N., \& Jackson, D. (2013). Working together to make Indigenous health care curricula everybody's business: A graduate attribute teaching innovation report. Contemporary Nurse, 46(1), 97-104.

Vogel, L. (2018). Residency programs grapple with new Indigenous cultural safety training requirement. CMAJ, 190(25), E778-E779.

West, R., Usher, K., \& Foster, K. (2010). Increased numbers of Australian Indigenous nurses would make a significant contribution to 'closing the gap' in Indigenous health: What is getting in the way? Contemporary Nurse, 36(1-2), 121-130.

Williamson, J., \& Dalal, P. (2007). Indigenising the curriculum or negotiating the tensions at the cultural interface? Embedding Indigenous perspectives and pedagogies in a university curriculum. The Australian Journal of Indigenous Education, 36(S1), $51-58$.

Wolfe, N., Sheppard, L., Le Rossignol, P., \& Somerset, S. (2018). Uncomfortable curricula? A survey of academic practices and attitudes to delivering Indigenous content in health professions degrees. Higher Education Research \& Development, 37(3), 649-662.

Wylie, L., \& McConkey, S. (2018). Insiders' insight: Discrimination against Indigenous peoples through the eyes of healthcare professionals. Journal of Racial and Ethnic Health Disparities, 6, 37-45.

Zhou, A. W., Boshart, S., Seelisch, J., Eshaghian, R., McLeod, R., Nisker, J., Richmond, C. A. M., \& Howard, J. M. (2012). Efficacy of a 3-hour Aboriginal health teaching in the medical curriculum: Are we changing student knowledge and attitudes? Health Education Journal, 71(2), 180-188. 